\title{
SUSTAINABLE CONSERVATION PERSPECTIVES FOR EPIPHYTIC ORCHIDS IN THE CENTRAL HIMALAYAS, NEPAL
}

\author{
ADHIKARI, Y. P. $.^{1 *}-$ FISCHER, A. $^{1}-$ PAULEIT, ${ }^{2}{ }^{2}$ \\ ${ }^{I}$ Geobotany, Department of Ecology and Ecosystem Management, Center for Food and Life \\ SciencesWeihenstephan, Technische Universität München, Hans-Carl-von-Carlowitz-Platz 2, \\ 85354 Freising, Germany \\ (phone: +49-8161-71-5855; fax: +49-8161-71-4738)
}

${ }^{2}$ Strategic Landscape Planning and Management, Department of Ecology and Ecosystem Management, Center for Food and Life Sciences Weihenstephan, Technische Universität München, Emil-Ramann-Str. 6, D-85354 Freising Germany

*Corresponding author

e-mail: yadhikari25@gmail.com

(Received $19^{\text {th }}$ Nov 2014; accepted $23^{\text {rd }}$ Dec 2014)

\begin{abstract}
Anthropogenic disturbances are major drivers of biodiversity loss. This is especially true for subtropical and tropical forest ecosystems. Epiphytes are plants that grow upon another plant (often trees) and, thus, fundamentally depend on their hosts. Epiphytic plants are diverse and can create important microcosms for many other organisms, including micro-organisms, insects, birds and mammals, which are rarely encountered on the floor. We identified the main habitat requirements for the conservation of epiphytic orchids and we outline key areas to focus on when designing management strategies for their protection and sustainable utilization. This approach is based on a review of the literature, as well as our own research on habitat requirements and the distribution of epiphytic orchids along a gradient from natural habitats to single trees in urban areas in the Kathmandu Valley, Nepal. Key areas to focus on for the sustainable conservation and utilization of epiphytic orchids are (i) habitat protection, (ii) habitat restoration, and (iii) the socio-economic relevance (utilization to fundraising) of conservation. While remnants of natural habitats are indispensable for the conservation of epiphytic orchid communities, groups of native trees in urban settings can still serve as stepping stones for epiphytic orchids. Therefore, the conservation of even small patches of primary forest within agricultural land areas or single trees within religious park complexes is crucial for the continual existence of epiphytic orchid populations in urban areas. Finally, we propose management concepts for the long-term maintenance of high epiphytic diversity. This framework has been developed for epiphytic orchids in the Himalayas, but can be more generally applied to other groups of epiphytes and other regions in the tropics and subtropics.
\end{abstract}

Keywords: biodiversity, epiphytic orchids, disturbance, land-use, protection, Himalayas, Nepal

\section{Introduction}

The loss of biodiversity over the last 100 years is immense, with nearly a third of plant species estimated to be threatened by extinction (GBR, 2010). Tropical and subtropical forests are among the most threatened ecosystems worldwide (Nieder et al., 2001). Land-use change by conversion to agriculture, settlement and infrastructure are considered to be the most important drivers of the loss of these forests and consequently of biodiversity decline (Sala et al., 2000). Epiphytic vascular plant species, such as orchids and ferns, and non-vascular species, such as bryophytes, algae, fungi and lichens, are especially threatened. This is due to their extreme microhabitats, often the trunk or branches of trees; however, some species survive in more anthropogenic habitats, such as on telegraph wires. The orchid family is the second largest family after Asteraceae in the flowering plant kingdom and it is estimated that more than 850 
species of orchids are existing in the Himalayan region (Acharya et al., 2011) with 437 species in Nepal alone (Rokaya et al., 2013).

Forests are an integral part of rural households' livelihood in Nepal (about $80 \%$ of the total population), as they provide daily subsistence needs (fuel, building materials, livestock feed and bedding, food and medicines) and generate income. However, they are also the main habitat of epiphytic plants, which thrive in the moist microclimate within the forest canopy. With their very special requirements (e.g. nutrients, light, and water availability), epiphytes are highly vulnerable to anthropogenic influences such as habitat degradation and deforestation (Wolf, 2005). Consequently, the collection, sale and utilization of a broad range of timber and non-timber forest products enhance exploitation, deforestation and degradation of remaining habitats (Bajracharya et al., 1994; Shrestha et al., 1999; Pimm and Raven, 2000; Rajbhandari and Bhattarai, 2001).

Most scientific research on orchids has been largely related to floristic exploration and taxonomic description, with little research addressing ecological and conservational issues (Sparrow, 1996; Zotz et al., 2001; Winkler et al., 2009). Epiphytes are ecologically important as they play a vital role in the ecosystem by producing relatively high amounts of organic matter on the host trees, providing living areas for other organisms and contributing to nutrient cycles, as many can fix atmospheric nitrogen (Nadkarni, 1994). Epiphyte and orchid diversity also appear to be very good indicators of the degree of disturbance suffered by a habitat in the urban environment (Newman, 2009). Both the distribution and abundance of epiphytic orchids, especially their habitat requirements and the human induced environmental changes to their habitats, were still poorly known in the Himalayan region until very recently. Studies of Adhikari and Fischer (2011) and Adhikari et al. (2012a) clearly showed that different orchid species vary in their response to anthropogenic disturbances (i.e. across a gradient from forest to urban area). As expected, most of the orchid species preferred less disturbed areas; however, several species will also grow on individual trees in polluted city centres (e.g. common species like Rhynchostylis retusa (L.) Blume and Vanda cristata Wall. ex Lindl.).

Knowledge and understanding of species distribution patterns is the basis for species conservation (Hirata et al., 2009). In particular for plants, and especially orchids, the main aspects to understand to design effective conservation strategies are: population ecology and dynamics (Annaselvam and Parthasathy, 2001; Winkler et al., 2009); lifecycle stages (Gomez et al. 2006); seed germination conditions, i.e. the relationship with mycorrhizal fungi and seedling establishment (Ackerman et al., 1996; Goode and Allen, 2009; Gowland et al., 2011; Light et al., 2011); pollination biology (Schiestl, 2005); and, the influence of different human land-use intensities (Adhikari et al., 2012a). Studying the relationship of epiphytic orchids to host tree characteristics and microhabitat quality (Köster et al., 2009) is a prerequisite to develop effective strategies for their conservation (Brooks et al., 2006). This is especially important given the high rate of population depletion and their relatively high vulnerability, e.g. due to highly specialized pollination systems and the requirement of mycorrhiza for germination. Climatic variables (temperature and precipitation) have been found to provide a good potential explanation for orchid species richness along the Himalayan elevational gradient (Acharya et al., 2011); such environmental conditions associated with altitude also exert a large influence on orchid species composition (Jacquemyn et al., 2005).

Nepal's forests are facing severe threats because of increasing demand on agricultural land, timber, fuel wood and fodder, and encroachment of the forest area for 
settlements. Nepal lost ca. 1.2 million ha of forest land (about $25 \%$ of its total forest cover) between 1990 and 2005 (FAO, 2005). Although overall deforestation rates have decreased since the 1990s, rates of loss of primary forests have increased significantly (FAO, 2005). This loss of primary forest will directly influence epiphytic ecosystems. At the current rate of deforestation, and without any control measures, the country will lose vital forest habitat.

We aim to outline a fundamental management concept for protection and sustainable utilization of epiphytic orchids in the tropics and subtropics. The framework will be based on existing knowledge of epiphytic orchids combined with what we have learned from our own studies on anthropogenic impacts on epiphytic orchid populations in the Kathmandu Valley, Nepal, in the central Himalayas (Adhikari et al., 2012a). Specifically, we ask the questions: How can existing populations of epiphytic orchids be managed under anthropogenic disturbances? What kind of landscape management is needed to ensure long-term protection of epiphytic species?

\section{Materials and methods}

Nomenclature of epiphytic orchids WCSP (2011).

\section{Study Area}

Our study site is the Kathmandu valley area, Nepal $\left(27^{\circ} 76^{\prime} \sim 62^{\prime} \mathrm{N} 85^{\circ} 25^{\prime} \sim 45^{\prime}\right.$ E) with the four closely located cities of Kathmandu, Bhaktapur, Lalitpur, and Banepa and represents the most urbanized place in Nepal, and, close to the city agglomeration, has unmanaged forest vegetation (Shivapuri Nagarjun National Park). The annual average rainfall is $1400 \mathrm{~mm}$ (Pant and Dangol, 2009) with the absolute maximum during summer time. The temperature in general is lowest $2{ }^{\circ} \mathrm{C}$ in winter and highest $28^{\circ} \mathrm{C}$ in summer. Kathmandu valley has Nepal's the largest urban population and hosts $12 \%$ of all households of Nepal (Zurick et al., 2005).

The natural vegetation of this valley is subtropical evergreen broad-leaved forest, nowadays remaining in the city area with a few isolated forest patches, several park areas and temple areas with groups of trees (Adhikari and Fischer, 2011). The most common tree species in Kathmandu valley are Schima wallichii, Alnus nepalensis and Ficus religiosa, while Castanopsis indica, Myrsine capitellata, Myrica esculenta, Pyrus pashia and Pinus roxburghii are more frequent in the surrounding forest areas. Our study area was defined as up to about $1700 \mathrm{~m}$ altitude in the northern part (national park), foot hills of the Kathmandu valley in the west and south, and up to Banepa city in the east (Fig. 1).

\section{Sampling}

We used a stratified systematic sampling strategy for the selection of sampling points within the study area (Fig. 1). We established 156 systematic sampling study points: host trees were selected on a plot less basis (Wolf et al., 2009). The study points were fixed around one tree of a host species having with at least one orchid species that was of $\geq 10 \mathrm{~cm}$ diameter breast height (dbh, i.e., diameter at $1.30 \mathrm{~m}$ ). At each point we studied the ten individual trees $(\mathrm{dbh} \geq 10 \mathrm{~cm})$ closest to the first selected host species in each point within 300 meters. Each tree was examined from different points, thereby assuring a clear view of all tree parts (Migenis and Ackerman, 1993). For larger trees, 
we used single-rope climbing techniques (Mitchell et al., 2002) and binoculars to sample host trees completely for epiphytic orchids. For each point tree sampled, we determined host characteristics, such as dbh, height, species identity, rugosity, sunlight intensity, host bark $\mathrm{pH}$. During field work at each point we cross-checked the geographical information system (GIS) results by estimating the percentage of land use. The time frame of our sampling covered the flowering period of most species, allowing for a high proportion of orchid species to be identified to species level.

For more details see Adhikari and Fischer (2011), and Adhikari et al. (2012a, b).

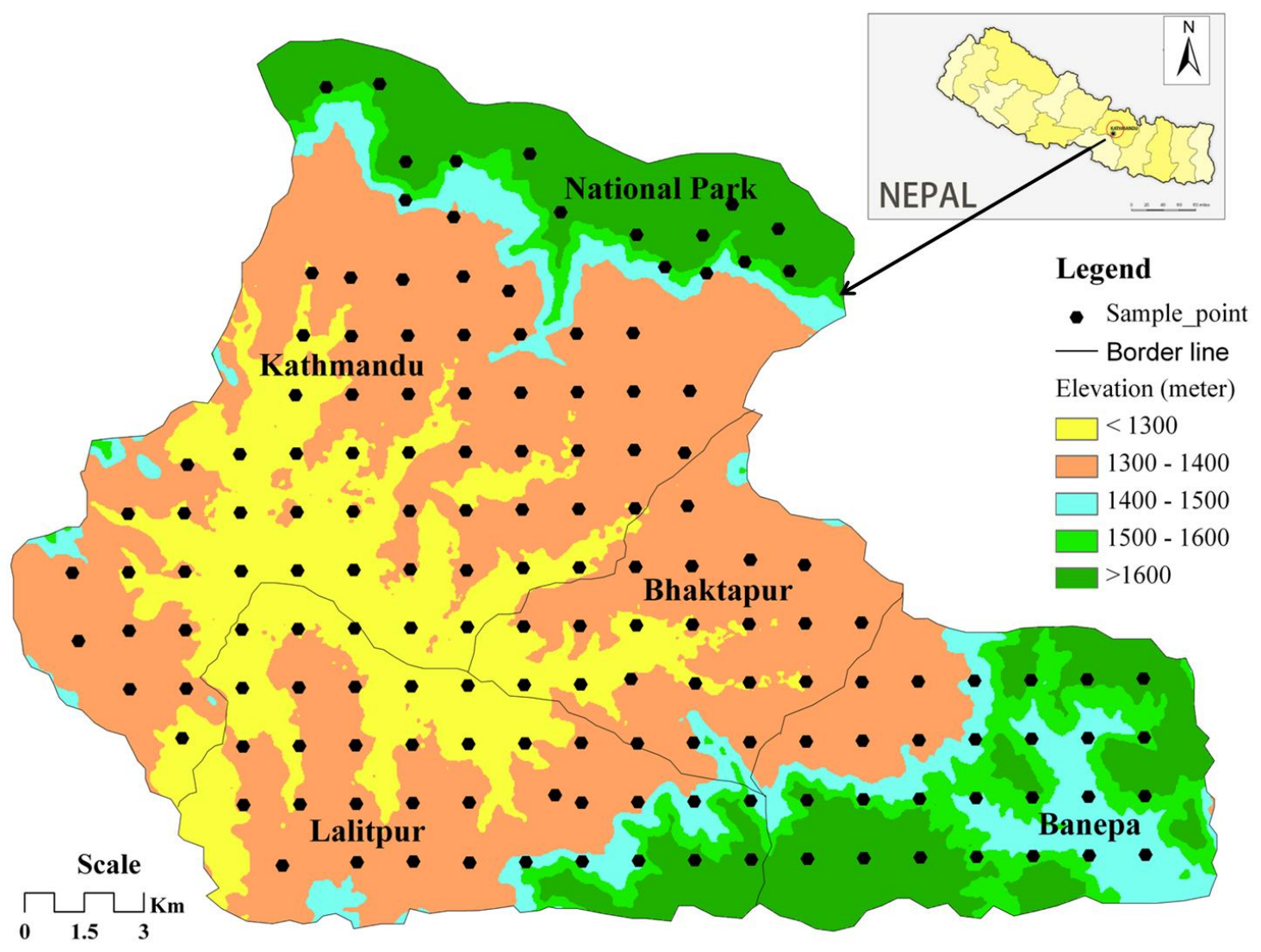

Figure 1. The study area geography including grid points $(1.5 \times 1.5 \mathrm{~km})$ in different human impact categories in different cities in the Kathmandu valley and National Park.

\section{Statistical Analysis}

All data were stored in a relational data base system in MS-Access. To analyse relationship between the orchid influencing factors we used spearman rank correlation coefficient. We analysed the similarity structure of the orchid influencing factors with a principle component analysis (PCA) with the function "rda" from the vegan package (Oksanen et al., 2011) in $\mathrm{R}$ ( $\mathrm{R}$ development core team 2.12.1). Variables were standardized to make different physical units comparable. Ellipses enveloping $90 \%$ of the trees with a selected orchid species respectively, without it were draw with the function "ordiellispe". 


\section{Identifying habitat requirements for conservation of epiphytic orchids}

The diversity and abundance of epiphytic orchids in different land use types are influenced by several variables including elevation, precipitation rhythm, bark rugosity, bark pH and sunlight intensity (Callaway et al., 2002; Adhikari et al., 2012a; b). Some orchids are generalists but others have very specific requirements, e.g. Psychilis monensis Sauleda frequency high on rough-barked substrates (Tupac et al., 2007). In Nepal, Rhynchostylis retusa was found to settle on a wide range of host trees but had higher abundance on some native species such as Ficus religiosa L. and Schima wallichii (DC.) Korth. (Adhikari and Fischer, 2011). For successful establishment of epiphytic orchids, trees with rugose bark (e.g. Schima wallichii) may be preferred hosts because seeds may become more easily lodged and moisture is retained for longer periods of time. Similarly, higher host bark water holding capacity enhances orchid abundance (Adhikari and Fischer, 2011). In addition, older and larger native tree-host species host higher numbers of epiphytic orchids than younger trees due to the time for colonization (Adhikari et al., 2012a). Since older and larger trees support more individuals and species of epiphytes, preserving such trees is an important contribution to maintain biodiversity (Heitz, 2005). Large exotic tree species with rugose bark are also present in the Kathmandu Valley (predominantly Populus euramericana Guinier), but Adhikari et al., (2012b) found only two of these trees (from several hundred) hosting epiphytic orchids showing that native trees are preferred habitat over exotic ones. This is not unexpected and shows that there has likely been some degree of coevolution between these epiphytes and their native host-trees. Variation among tree species for different bark chemicals can also influence orchid seed germination and early growth (Frei and Dodson, 1972). Thus, even visually suitable trees may be unsuitable due to other factors such as bark chemistry, which may explain the preference towards native host species. Köster et al. (2011) found that both host species composition (mostly due to native species) of a forest stand and their characteristics as micro-sites influence epiphytic species diversity, this is similar in Kathmandu valley (Adhikari et al., 2012a).

Increased knowledge of host-tree characteristics and other variables, from the example of epiphytic orchids in the Kathmandu Valley, Nepal (Fig. 1; Adhikari et al., $2012 \mathrm{~b}$ ) is shows that orchid protection and conservation is not an easy task. Different epiphytic orchid species interact differently with the given set of environmental factors (Fig. 2): for Vanda cristata there is no single environmental factor of special influence, while for $R$. retusa high bark $\mathrm{pH}$ and light availability are important. Similarly, Acampe rigida (Buch.-Ham. ex Sm.) Hunt prefers light and a large dbh (diameter at breast height) of the host tree, Bulbophyllum affine Wall. ex Lindl. occurs in areas more exposed to wind, while for Dendrobium bicameratum Lindl. both exposure to wind and bark rugosity are important. Therefore, in order to protect a diversity of orchid species, it is the diversity of epiphytic habitat conditions (i.e. micro-site conditions) which have to be protected.

The selection of suitable tree species (i.e. native ones) for reforestation purposes in conservation programs in subtropical regions is essential for future epiphytic species protection, in urban areas and elsewhere. Managed and natural forest patches, tree plantations (Hietz, 2005) and even single, old and native host trees in urbanized areas may be considered as important epiphytic habitats (Köster et al., 2009). 

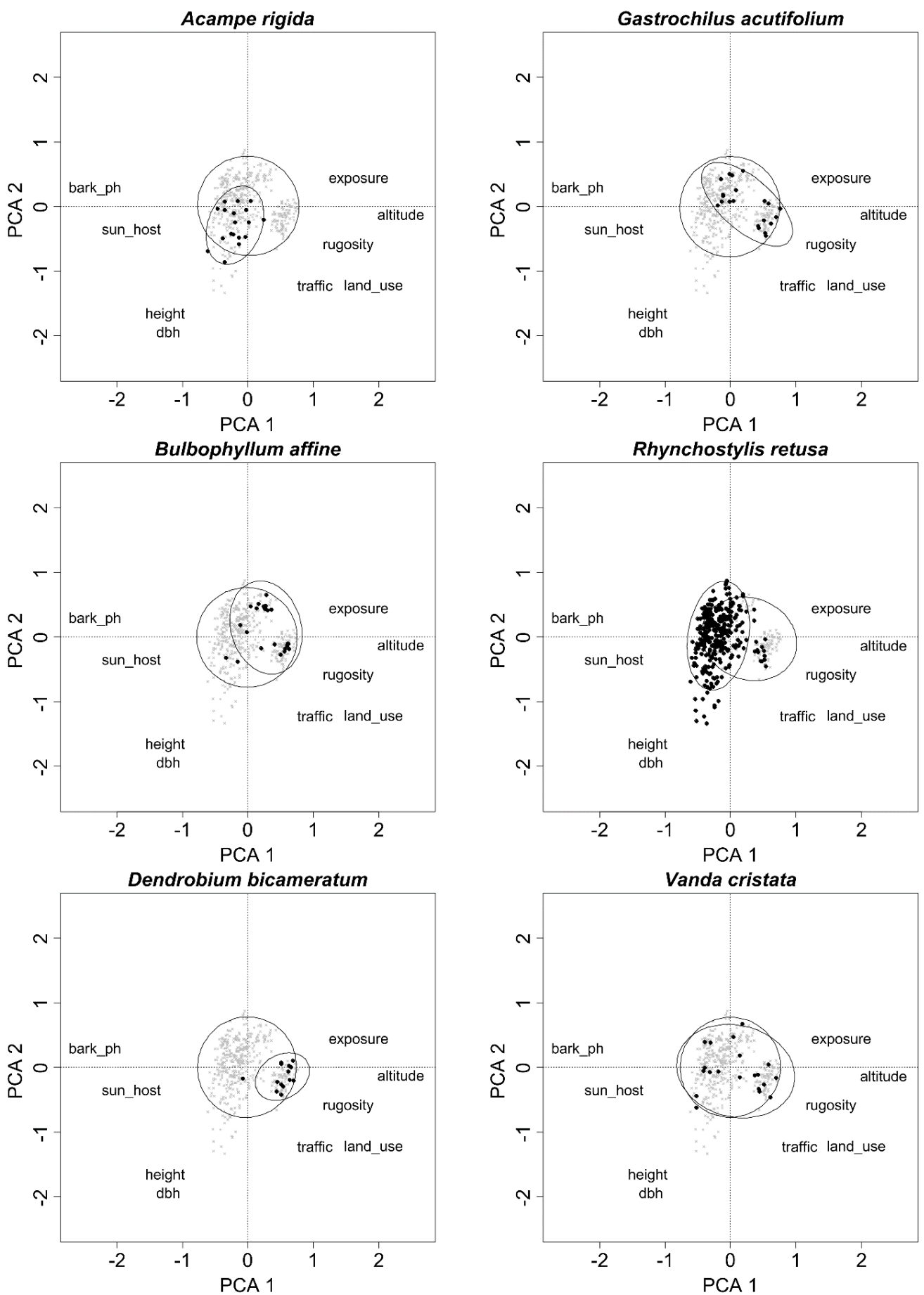

Figure 2. Principal component analysis of host tree species in the Kathmandu Valley (for methods and study area see Adhikari et al. 2012b) based on host tree characteristics. For each orchid species the tree individuals which host this orchid are displayed as black dots whereas tree individuals without this orchid are the grey dots. Ellipses envelop $90 \%$ of all tree individuals hosting a selected orchid species, respectively hosting it or not. If the ellipses overlap more or less totally the orchid does not depend on the analyzed site conditions offered by the host (e.g. Vanda cristata). If, however, the ellipses only overlap a bit, the orchid is strongly dependent on the indicated site conditions (e.g. Rhynchostylis retusa). Site conditions are: host bark $\mathrm{pH}$, sunlight intensity, exposure to wind, bark rugosity, land use intensities, altitude, host height and dbh (diameter at breast height), and vehicle traffic 
Other factors that potentially play a role to develop conservation planning schemes of epiphytic communities include understanding how traditional management practices adopted in commercial monocultures can affect epiphytic communities (Barthlott et al., 2001).

\section{Key elements for conservation planning}

Conservation of epiphytic orchids has to address three aspects: (i) the elements that should be protected, (ii) the activities that should be carried out to protect valuable elements, and (iii) the socio-economic background of conservation (Fig. 3).

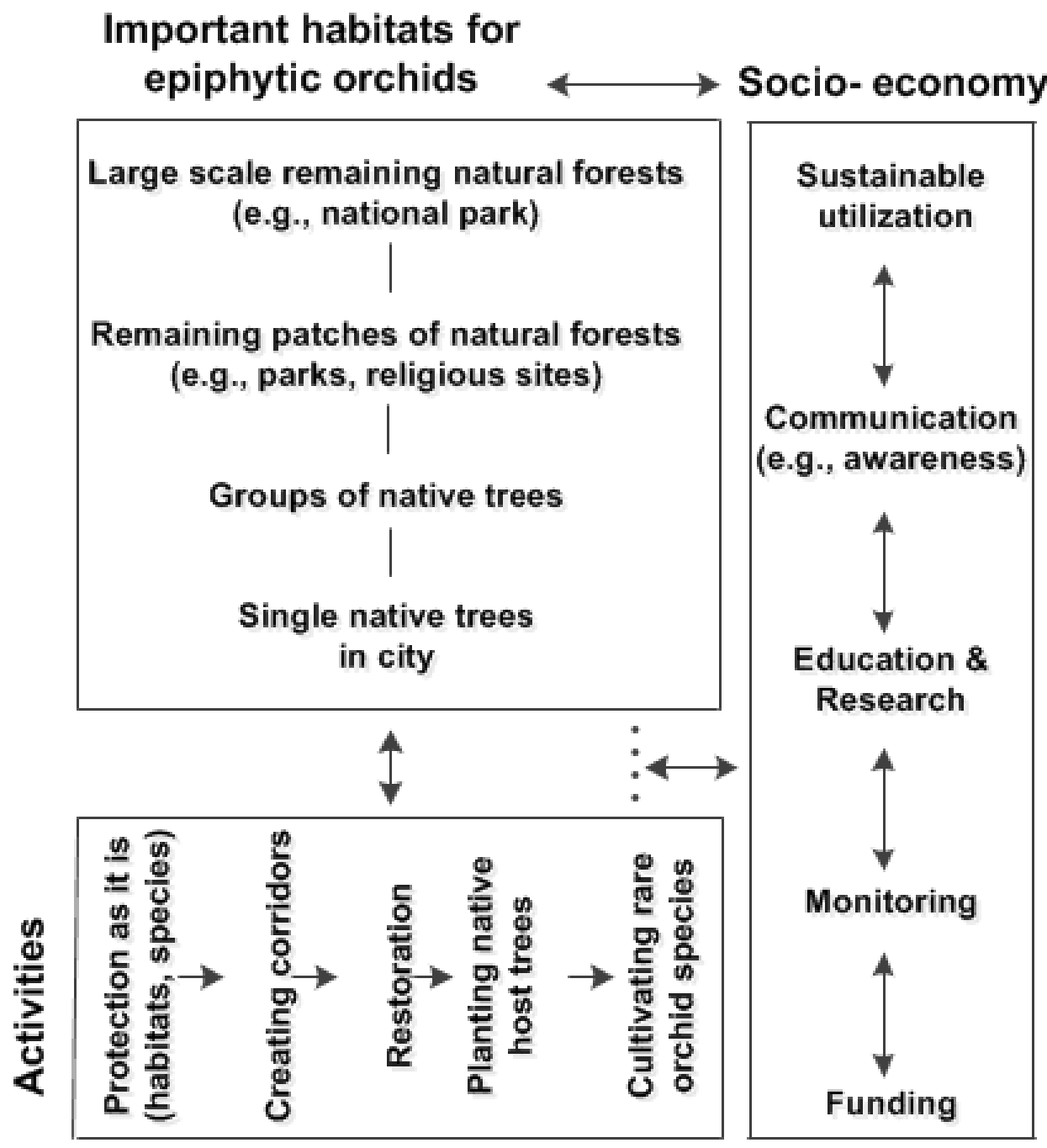

Figure 3. Key elements for conservation of epiphytes in subtropics

To establish acceptance for orchid diversity protection in the community, public awareness has to be increased, in the long run, by educational programs. The success of activities has to be evaluated by monitoring programs. The activities need to be funded, which again requires public acceptance (Cao et al., 2011). In the following we will discuss these aspects and outline a plan for epiphytic orchid protection in settled areas of the subtropics. 


\section{Habitat protection and land use planning}

Protection of remaining habitats for epiphytic orchids in the subtropics is essential. Conservation strategies for epiphytic species have to include preservation of the remaining areas of primary and near-natural forests (Sosa and Platas, 1998). While forests are most important for the conservation of epiphytic orchids, also small groups of trees and single trees can make a valuable contribution to conserve epiphytic orchids. In particular, old trees in the Himalayas (e.g. Ficus religiosa and Schima wallichii) need to be protected because these host trees harbor high numbers of epiphytic plants. Single host trees can often be found in religious temple complexes and groups of trees within remnant forest patches. Both these habitats should therefore be prioritized for protection in city areas as they host the richest communities of epiphytic orchids (Adhikari and Fischer, 2011). Protection of the remnant forests, against further direct anthropogenic activities (e.g. logging, lopping and fuel wood collection) is essential in rural as well as in urbanized areas.

\section{Species protection}

Favourable conditions for epiphytic communities in a particular landscape (Adhikari et al., 2012a), the availability of suitable host trees (Callaway et al., 2002; Hirata et al., 2009), and seedling establishment (Werner and Gradstein, 2008) are most important for maintaining epiphytic communities. Orchid seeds are very small and contain limited energy reserves, the relationship between orchids and mycorrhizal fungi allows the orchid seed to germinate and the seedling to establish (Zotz et al., 2001; Dearnaley, 2007; Gowland et al., 2011). Although there are species-specific associations between orchids and mycorrhizal fungi (Gowland et al., 2011), generalist culturable fungi may be useful for propagation of rare orchid species and thus may save some species from extinction (Chen et al., 2012). To enhance the resilience of the epiphyte vegetation to logging it thus appears wise to spare not only single but also a varied species group of trees in order to maintain the available diversity of mychorrizal fungi (Heitz, 2005; Higuera and Wolf, 2010).

Strategies to protect over-collected, endangered and rare ornamental species should also be included in propagation projects as a participation approach (Sosa and Platas, 1998). Maintaining the species in ex-situ conservation (e.g. botanical gardens or nurseries) is one of the alternative strategies (Koirala et al., 2010). Orchid species collected from areas which are subject to clear cutting from urban areas may be replaced on a suitable host tree in the ex-situ conservation areas by government and research institutes. In 2012, Nepal's Ministry of Forest and Soil Conservation published guidelines ("Nirdeshika") for how to collect and cultivate orchids; around 20 species are allowed to be propagated in tissue culture, including Acampe papillosa (Lindl.) Lindl., Coelogyne cristata Lindl., C. flavids Hook. Fil. Wall. ex., and Dendrobium amoenum Wall. ex Lindl.. This will enhance local populations of these particular orchid species and also, through increased awareness, potentially benefit conservation efforts of other orchids.

\section{Restoration and Stepping stones}

Human activities alter the structure of landscape and ecosystems worldwide, often drastically by converting forestland into agricultural and urban land. In such areas only isolated forest patches, small groups of trees or single tree individuals remain 
(Nadkarni, 1994) and their removal affects the whole epiphytic community ecosystem. In Kathmandu Valley, habitat modification from natural to high intensity land-use was associated with a decline in the species richness and abundance of epiphytic orchids (Adhikari et al., 2012b). This was mainly driven by the reduced diversity of host species creating a more homogenous microclimate in the disturbed and secondary vegetation compared to the primary forest.

Habitat degradation is one of the major problems associated with over deforestation, exploitation and urbanization for epiphytic orchids in the Himalayas (Rajbhandari and Bhattarai, 2001). The first step for improvement is to restore the degraded habitats so that the native species of the area can be conserved in their natural habitats; a second step is the re-introduction of those species that historically occurred in an area (Shashidhar and Kumar, 2009). A suitable approach would be (i) to protect old trees in rural and urban areas as carriers of epiphytes since old trees are not only crucial for those epiphytes but also may serve as a seed source for the recruitment of orchids in the nearby regenerating forests (Wolf, 2005); (ii) to plant native tree species when replacing the older trees in urban habitats, to ensure these areas are maintained as stepping stones for epiphytic plants. Such stepping stones help link existing patches and host trees, providing opportunities for dispersal, facilitating gene flow between populations, and increasing the likelihood that the patches will be colonised by epiphytic orchids (Barnes and Lowell, 1999). Therefore, protection of existing habitats needs to be complemented by the establishment of such stepping stones so that the fragments can be connected and a network of such areas are formed; this will also benefit the conservation of other native species and, thus, biodiversity in general.

\section{Planting "trees for the future" for epiphytic orchids}

The development of a conservation action plan for endangered tree host species, as well as orchid species, is urgently needed. Ex-situ propagation of orchids is beneficial but will not lead to long-term population establishment without there being suitable future habitat for these plants. Common native host species usually offer the best microhabitat for epiphytes (Adhikari et al., 2012a) and even native single individual trees can play a major role in the conservation of biodiversity in tropical and subtropical urban regions (Turner et al., 1994). To find the best sites to plant such "trees for the future" is a task for landscape planning (urban forestry), but should focus on creating a network of native trees and patches across the urban areas. In the long term, conservation management efforts should focus on increasing overall numbers of native trees in the landscape, especially in parks and religious sites of urban areas.

\section{Sustainable utilization}

Sustainable conservation of epiphytic orchids in developing countries will only be successful if it can be linked to the socio-economic system (Brooks et al., 2006) or, in other words: if it can provide economic benefits to the local people. In the case of the Himalayan region there are several potential ways to do this. Areas that are rich in epiphytic orchid species could be used for promotion for eco-tourism (Koirala et al., 2010). Then the local stakeholders can earn some income while at the same time increasing awareness for the need to conserve epiphytes. In the Himalayas, up to now, there were no specific or model conservation activities adopted, but some private hotels 
in Daman (Makawanpur district) and Bandipur (Tanahun district) do use collected orchids for decoration, attracting tourist and conservation awareness.

As the human population increases, activities such as the collection of native flora for medicinal uses puts a strain on the natural populations, e.g. a previously common orchid, Dendrobium densiflorum Lindl., around the Kathmandu Valley, is now very rare because the bulbs were collected illegally for medicinal purposes (Shrestha, 2003). Thus, a second possibility could be the promotion of the sustainable harvest of these species, as has been suggested in the Andes (Acebey et al., 2010). Target species, of importance in local culture, should be identified for mass propagation by tissue culture followed by cultivation for ornamental and medicinal uses. Selective collection may conserve and facilitate the restoration of epiphyte numbers and diversity locally. It cannot, however, safeguard epiphyte diversity on a regional scale (Wolf, 2005) and more ecological information would be required for this as well as specific guidelines for sustainable use. Sustainable utilization could be achieved by a number of ways including the collection only of abundant and more widely distributed species or collection could be restricted to harvesting from the lower parts of the trees (Wolf and Konings, 2001). Alternative good strategies for epiphytic conservation in the longer term include, only harvesting some of the pseudobulbs, or just the flowers or, further, collection restricted to fallen orchids (Demetria and Ticktin, 2011). Sustainable harvesting systems may really work, as has been reported from Costa Rica (Brooks et al., 2006); however, monitoring is required to evaluate the concrete consequences of harvesting activities. Nevertheless, sustainable harvest needs to be combined with community-based propagation approaches for target species because of their very low population growth rates. Lastly, awareness has to be raised in the local communities so that the living orchid is more valuable than those collected and sold, e.g. by implementing eco-tourism facilities. In the Himalayas there are many possibilities for orchid conservation in community forests, and these can be achieved, with the help of local communities. In our studies, so far, we have little evidence that local people are aware of the importance of the orchids and the surrounding habitat (Adhikari et al., 2012a). Future work should address this lack of knowledge and how it can be implemented at both the local and the regional level.

\section{Communication and education}

There is a need to provide awareness activities, training programs, and information on the habitat requirements of epiphytic orchids to government and stakeholders, so as to develop management strategies for their conservation (Adhikari et al., 2012a). To succeed, wildlife conservation policy will have to be a mix of protectionism, community involvement, public relations, conservation education, and revenue sharing (Hackel, 1999) and this is also true for wild epiphytic community conservation in the Himalayas. Furthermore, educational institutions should promote research on conservation modalities and scientific cultivation of wild and endangered epiphytic orchid species. Thus, a strategy for communication to the public should focus on the beauty, medicinal use and eco-tourism potential of these species and their host trees (e.g., Ficus religiosa). The way, however, is still long and educating the younger generation in schools, for example, will be essential to reach this goal. 


\section{Monitoring and funding}

Without monitoring it is impossible to provide a systematic evaluation of which strategies are best suited for different conservation tasks (Brooks et al., 2006). Monitoring of the species populations should always be part of a management plan for sustainable use (Wolf, 2001). Long-term monitoring of potentially vulnerable sites for epiphytes is also advised, especially of those sites that are outside current protected areas. Under sustainable multifunctional epiphyte management, it is necessary to include specific spatial distributions of species and objectives apply in planning and monitoring programs. To implement all these kinds of activities money is needed. Stake holders, government, decision makers, NGOs and INGOs therefore need to search for funding for conservation activities of epiphytic orchids, in Himalayas as well as in the whole tropics and subtropics.

\section{Planning Scheme}

We suggest that effective conservation of epiphytic orchids will require: (i) Protection of existing forests and use of forest management practices that maintain the canopy diversity. (ii) Protection of existing old patches of trees as well as single remaining host tree individuals in agricultural or urban areas as small "ecological island" habitats for epiphytic orchids, and as stepping stones between larger forest patches as carriers of existing epiphytic orchids. (iii) Planting of new (mainly native) trees, as hosts for the future, in groups instead of single isolated individuals; trees should especially be planted in areas where orchids still exist to provide more trees for orchid population growth (e.g. along riparian system). (iv) Planting of trees in urban settings with suitable host characteristics (e.g. older and larger trees, rougher bark, low $\mathrm{pH}$, exposed to wind, and reduced human impact). (v) Planting of religious relevant trees in areas where the orchid species is recently missing because such tree species have a high degree of acceptance among people. (vi) Public education awareness campaign programs organized through various extension methods and through mass media. And finally, (vii) Government and research institutes, including educational institutions, should promote research on conservation modalities and scientific cultivation; especially for endangered orchid species there must be suitable places where recovery management plans can be established (e.g. national parks).

\section{Conclusions}

There is a dire need to effectively manage the forest and biodiversity of the Himalayas for the economic, cultural, and political stability of the country as well as to meet international obligations. Decentralization of conservation programs (e.g. community-based) and local institution empowerment are the success for epiphyte conservation. When the life-span of a conservation project expires, the success of any project will depend on the ability of the local communities to manage their resources over the long term (Brooks et al., 2006). Therefore, there is a need for applying conservation practices in the area where epiphytes play ecological roles in the forest canopy of subtropical regions. Species need to be able to migrate when the conditions are not ideal for their sustenance and survival. 
Acknowledgments. We thank H. S. Fischer and S. E. Zytynska for language and comments on the manuscripts. We are indebted to TUM Graduate School for the research grant.

\section{REFERENCES}

[1] Acebey, A., Kromer, T., Maass, B.L., Kessler, M. (2010): Ecoregional distribution of potentially useful species of Araceae and Bromeliaceae as non-timber forest products in Bolivia. - Biodiversity Conservation 19: 2553-2564.

[2] Ackerman, J.D., Sabat, A., Zimmerman, J.K. (1996): Seedling establishment in an epiphytic orchid: an experimental study of seed limitation. - Oecologia 106: 192-198.

[3] Acharaya, K.P., Vetaas, O.R., Birks, H.J.B. (2011): Orchid species richness along Himalayan elevational gradients. -Journal of Biogeography 38: 1821-1833.

[4] Adhikari, Y.P., Fischer, A. (2011): Distribution pattern of the epiphytic orchid Rhynchostylis retusa under strong human influence in Kathmandu valley, Nepal. Botanica Orientalis - Journal of Plant Science 8: 90-99.

[5] Adhikari, Y.P., Fischer, H.S., Fischer, A. (2012a): Micro-site conditions of epiphytic orchids in a human impact gradient in Kathmandu valley, Nepal. - Journal of mountain Science 9:331-342, DOI: 10.1007/s11629-009-2262-1.

[6] Adhikari, Y.P., Fischer, H.S., Fischer, A. (2012b): Host tree utilization by epiphytic orchids in different land-use intensities in Kathmandu valley, Nepal. - Plant Ecology 213: 1393-1412, DOI: 10.1007/s11258-012-0099-0.

[7] Annaselvam, J., Parthasathy, N. (2001): Diversity and distribution of herbaceous vascular epiphytes in a tropical evergreen forest at Varagalaiar, Western Ghats, India. Biodiversity Conservation 10: 317-329.

[8] Bajracharya, D.M., Shakya, L.R., Chettri, M. (1994): Need for conservation of some of endangered orchids of Ilam district. - In: Proceeding of the Second National Conference on Science and Technology. Nepal Academy of Science and Technology (NAST), Kathmandu, Nepal. Pp663-669.

[9] Barnes, T.G., Lowell, A. (1999): A Guide to Urban Habitat Conservation Planning. - the University of Kentucky Cooperative Extension Service, http://www.ca.uky.edu.

[10] Barthlott, W., Neuerburg, V.S., Nieder, J., Engwald, S. (2001): Diversity and abundance of vascular epiphytes: a comparison of secondary vegetation and primary montane rain forest in the Venezuelan Andes. - Plant Ecology 152: 145-156.

[11] Brooks, J.S., Franzen, M.A., Holms, C.M., Grote, M.N., Mulder, M.B. (2006): Testing hypotheses for the success of different conservation strategies. - Conservation Biology 20: $1528-1538$.

[12] Callaway, R.M., Reinhart, K.O., Moore, G.W., Moore, D.J., Pennings, S.C. (2002): Epiphyte host preferences and host traits: mechanisms for species-specific interactions. Oecologia 132: 221-230.

[13] Cao, S., Xu, C., Chen, L., Shankman, D., Wang, C., Wang, X., Zhang, H. (2011): Excessive reliance on afforestation in China's arid and semi-arid regions: lessons in ecological restoration. - Earth Science Reviews 104: 240-245.

[14] Chen, J., Wang, H., Guo, S.X. (2012): Isolation and identification of endophytic and mycorrhizal fungi from seeds and roots of Dendrobium (Orchidaceae). - Mycorrhiza 22: 297-307.

[15] Chung, M.Y. (2009): Low levels of genetic variation within populations of the four rare orchids Gymnadenia cucullata, Gymnadenia camtschatica, Amitostigma gracile, and Pogonia minor in South Korea: indication of genetic drift and implications for conservation. - Plant Systematic and Evolution 281: 65-76.

[16] Dearnaley, J.D.W. (2007): Further advances in orchid mycorrhizal research. -Mycorrhiza 17: 475-486. 
[17] Demetria, M.C., Ticktin, T. (2011): Demographic effects of harvesting epiphytic bromeliads and an alternative approach to collection. - Conservation Biology 25: 797807.

[18] Dressler, R.L. (1993): Phylogeny and classification of the orchid family. - Dioscorides Press, Portland, OR.

[19] FAO (2005): Nepal Country Report. Global Forest Resources Assessment. - Country Report No. 192. Rome.

[20] Frei, O.P., Dodson, C.H. (1972): The chemical effect of certain bark substrates on the germination and early growth of epiphytic orchids. - B. Torrey Bototanical Club 99: 301307.

[21] Fischer, A., Blaschke, M., Baessler, C. (2011): Altitudinal gradients in biodiversity research: the state of the art and future perspectives under climate change aspects. AFSV (urn: nbn: de: 0041.afsv-01140).

[22] GBR (2010): Global Biodiversity Outlook 3. - Secretariat of the convention on biological diversity, Montreal, pages 9 (gb03-final-en1.pdf).

[23] Garcia, M.B., Goni, D., Guzman, D. (2010): Living at the Edge: Local versus Positional Factors in the Long-Term Population Dynamics of an Endangered Orchid. Conservation Biology 24: 1219-1229.

[24] Gomez, N.R., Tremblay, R.L., Ackerman, E.M. (2006): Distribution of life cycle stages in a lithophytic and epiphytic orchid. - Folia Geobotany 51: 107-120.

[25] Goode, L.K., Allen, M.F. (2009): Seed germination conditions and implications for establishment of an epiphyte, Aechmea bracteata (Bromeliaceae). - Plant Ecology 204: $179-188$.

[26] Gowland, K.M., Wood, J., Clements, M.A., Nicotra, A.B. (2011): Significant phorophyte (substrate) bias is not explained by fitness benefits in three epiphytic orchid species. Ammerican Journal of Botany 98: 197-206

[27] Hackel, J.D. (1999): Community conservation and the future of Africa's Wildlife Conservation Biology 13: 726-734.

[28] Heitz, P. (2005): Conservation of vascular epiphyte diversity in Mexican coffee plantations. - Conservation Biology 19: 391-399.

[29] Higuera, D., Wolf, J.H.D. (2010): Vascular Epiphytes in dry oak forests show resilience to anthropogenic disturbance, Cordillera Oriental, Colombia. - Caldasia 32: 161-174.

[30] Hirata, A., Kamijo, T., Saito, S. (2008): Host trait preferences and distribution of vascular epiphytes in a warm-temperate forest. - Plant Ecology 201: 247-254.

[31] Jacquemyn, H., Micheneau, C., Roberts, D.L., Pailler, T. (2005): Elevational gradients of species diversity, breeding system and floral traits of orchid species on Re'union Island. Journal of Biogeography 32: 1751-1761.

[32] Köster, N., Friedrich, K., Nieder, J., Barthlott, W. (2009): Conservation of epiphyte diversity in an Andean landscape transformed by human land use. - Conservation Biology 23: 911-919.

[33] Köster, N., Nieder, J., Barthlott, W. (2011): Effect of host tree traits on epiphyte diversity in natural and anthropogenic habitats in Ecuador. - Biotropica 43: 685-694.

[34] Koirala, P.N., Pyakurel, D., Gurung, K. (2010): Orchids in Rolpa district of Western Nepal: Documentation, stock, trade and conservation. - Banko Janakari 20: 3-13.

[35] Light, M.H.S., Koopowitz, H., Marchant, T.A. (2003): The impact of climatic, edaphic and physiographic factors on the population behaviour of selected temperate and tropical orchids. - In: Dixon KW, Kell SP, Barrett RL, Cribb PJ (eds.), Orchid Conservation. Natural History Publications, Kota Kinabalu, Sabah. pp 159-182.

[36] Migenis, L.E., Ackerman, J.D. (1993): Orchid-phorophyte relationships in a forest watershed in Puerto Rico. - Journal of Tropical Ecology 9: 231-240. 
[37] Mitchell, A.W., Secoy, K., Jackson, T. (2002): The Global Canopy handbook. Techniques of access and study in the forest roof. - Global Canopy Programme, Oxford.

[38] Nadkarni, N.M. (1994): Diversity of species and interactions in the upper tree canopy of forest ecosystems. - American Zoology 34: 70-78.

[39] Newman, B. (2009): Orchids as indicators of ecosystem health in urban bush land fragments. - PhD thesis submitted to Murdoch University, Australia.

[40] Nieder, J., Prosperi, J., Michaloud, G. (2001): Epiphytes and their contribution to canopy diversity. - Plant Ecology 153: 51-63.

[41] Oksanen, J., Blanchet, F.G., Kindt R., Legendre P., O’Hara, R.B., Simpson, G.L., Solymos, P., Stevens, M.H., Wagner, H. (2011): Vegan: Community ecology package. $\mathrm{R}$ package version 2.12.1 http://CRAN.R project.org/package=vegan.

[42] Pimm, S.L., Raven, P. (2000): Biodiversity-extinction by numbers. - Nature 403: 843845.

[43] Rajbhandari, K.R., Bhattarai, S. (2001): Beautiful Orchids of Nepal. - Keshab R. Bhandari and Sushila Bhattarai, Kathmandu, Nepal.

[44] Rokaya, M.B., Raskoti, B.B., Timsina, B., Münzbergová, Z. (2013): An annotated checklist of the orchids of Nepal. - Nordic Journal of Botany 31: 511-550.

[45] Sala, O.E., Chapin, F.S., Armesto, J.J. et al. (2000): Global biodiversity scenarios for the year 2100. - Science 287: 1770-1774.

[46] Schiestl, F.P. (2005): On the success of a swindle: pollination by deception in orchids. Naturwissenschaften 92: 255-264.

[47] Shrestha, T.K. (2003): Wildlife of Nepal: a study of renewable resources of Nepal Himalayas. - Reprint, Kathmandu, Nepal.

[48] Shrestha, A.B., Cameron, P.W., Paul, A.M., Jack, E.D. (1999): Maximum temperature trends in the Himalaya and its vicinity: An analysis based on temperature records from Nepal for the period 1971-94. - Journal of Climate 12: 2775-2786.

[49] Shashidhar, K.S., Kumar, A.N.A. (2009): Effect of climate change on orchids and their conservation strategies. - Indian Forester 135: 1039-1049.

[50] Sosa, V., Platas, T. (1998): Extinction and persistence of rare orchids in Veracruz, Mexico. - Conservation Biology 12: 451-455.

[51] Sparrow, O. (1996): Orchids in the Nepal Himalaya distribution and ecology, part 3. Orchid Review 104: 105-108.

[52] Tupac, O.J., Aragon, S., Ackerman, J.D. (2007): Site variation in spatial aggregation and phorophyte preference in Psychilis monensis (Orchidaceae). - Biotropica 39: 227-231.

[53] Turner, I.M., Tan, H.T.W., Wee, Y.C., Ibrahim, A.B., Chew, P.T., Corlett, R.T. (1994): A study of plant species extinction in Singapore lessons for the conservation of tropical biodiversity. - Conservation Biology 8: 705-712.

[54] WCSP (2011): World Checklist of Selected Plant Families. Facilitated by the Royal Botanic Gardens, Kew. Published on the Internet; http://apps.kew.org/wcsp/ Retrieved.

[55] Werner, F.A., Gradstein, S.R. (2008): Seedling establishment of vascular epiphytes on isolated and enclosed forest trees in an Andean landscape, Ecuador. - Biodiversity Conservation 17: 3195-3207.

[56] Winkler, M., Hülber, K., Hietz, P. (2009): Population dynamics of epiphytic orchids in a metapopulation context. - Annals of Botany 104: 995-1004.

[57] Wolf, J.H.D., Konings, C.J.F. (2001): Toward the sustainable harvesting of epiphytic bromeliads: a pilot study from highlands of Chiapas, Mexico. - Biological Conservation 101: 23-31.

[58] Wolf, J.H.D. (2005): The response of epiphytes to anthropogenic disturbance of pine-oak forests in the highlands of Chiapas, Mexico. - Forest Ecolgy and Management 212: 376393. 
[59] Wolf, J.H.D., Gradstein, S.R., Nadkarni, N.M. (2009): A protocol for sampling vascular epiphyte richness and abundance. - Jornal of Tropical Ecology 25: 107-121.

[60] Zimmerman, J.K., Olmsted, I.C. (1992): Host tree utilization by vascular epiphytes in a seasonally inundated forest (Tintal) in Mexico. - Biotropica 24: 402-407.

[61] Zotz, G., Thomas, V., Hartung, W. (2001): Ecophysiological consequences of differences in plant size: abscisic acid relationships in the epiphytic orchid Dimerandra emarginata. Oecologia 129: 179-185.

[62] Zurick, D., Pacheco, J., Shrestha, B., Bajracharya, B. (2005): Atlas of the Himalaya. International Centre for Integrated Mountain Development (ICIMOD) pp 17-90. 